\title{
En torno a la cultura popular y los conceptos de cultura: Contribuciones a un debate permanente
}

\footnotetext{
Antes que el faraón Psamético subiera al poder, los egipcios creían ser el pueblo más antiguo del mundo. Pero después de las investigaciones de este rey, opinan que los frigios son más antiguos que ellos, y ellos más que todos los restantes.

Lo que ocurrió es que como Psamético no veía forma de llegar a una conclusión clara, pese a todas sus averiguaciones, ideó lo siguiente para saber, de una vez, quiénes habían sido los primeros en poblar el mundo.

Entregó a un pastor dos niños recién nacidos, hijos de un par de familias elegidas al azar, y le ordenó cómo tenía que criarlos. Nadie debería pronunciar una sola palabra delante de ellos, y los pequeños yacerían completamente solos en una cabaña solitaria. A las horas del alimento, el pastor les llevaría sus cabras para que pudieran tomar la leche necesaria, ocupándose asimismo de que nada les faltara.

Psamético dispuso esto porque deseaba saber qué palabras dirían los pequeños cuando llegaran a la edad de hablar.

$\mathrm{Y}$ así sucedió.

Durante dos años había cuidado el pastor a los niños cuando un día, al abrir la puerta de la cabaña, estos corrieron a su encuentro con las manos extendidas gritando:

-iBecos!

La primera vez, el hombre no hizo demasiado caso, pero al ver que los niños repetían la palabra en cuanto él se presentaba a atenderles, lo notificó a su señor $\mathrm{y}$, por orden de Psamético, le llevó los pequeñuelos a palacio. Al escuchar el faráon aquella palabra con sus propios oídos, mandó averiguar qué pueblo empleaba la voz becos. Por fin se supo que así llaman los frigios al pan.

Obtenida esta prueba, los egipcios admitieron que el pueblo frigio era todavía más antiguo que el suyo.

Reproduzco la historia tal como la oí de los sacerdotes de Hefaistos, en Menfis. Los helenos, desde luego, adornan el suceso con una serie de disparatados detalles, y afirman que Psamético confió el cuidado de las dos criaturas a unas mujeres a las que previamente había mandado cortar la lengua.
}

HERODOTO, El asombro de Herodoto (Barcelona: Bruguera, 1975), edición de Werner Keller.

Comenta W. Keller este texto de Herodoto diciendo que el faraón mencionado debió de ser Psamético II y que «becos» parece, en efecto, palabra frigia encontrada en diversas inscripciones. También añade que 
otras testas regias como Federico II Hohenstauffen (1212-50) y Jacobo IV, rey de Escocia (1488-1513) dieron en concebir y realizar experimentos semejantes. En ambos casos se llegó a la conclusión de que la lengua originaria de la humandiad había sido el hebreo. A. L. Kroeber señala que el emperador mogol Akbar llevó a cabo otro experimento parecido con el propósito de descubrir la "religión natural" de la humanidad.

\section{LA CUltura POPUlar y LOS CONCEPTOS DE CULTURA}

Es, después de todo, no sólo con estatuas, (o pinturas, o poemas) que estamos tratando, sino con los factores que hacen que esas cosas parezcan importantes a quienes las hacen o las poseen...

ClifFORD GEERTZ, Local Knowledge (New York, Basic Books, 1983)

Las aproximaciones a eso que aún venimos denominando como "cultura popular" han estado, en general, muy condicionadas por la visión que de este fenómeno nos dieron los estudiosos del folklore desde mediados del siglo pasado. A menudo, los trabajos sobre tales manifestaciones tenidas por "populares" continúan siendo - todavía - poco más que una discusión en torno a la denominación, competencias o necesidad del folklore en cuanto a ciencia que habría de ocuparse de un supuesto "saber popular".

La preocupación por el mismo no era tan nueva -como luego veremos-, pero no cabe duda de que durante el Romanticismo cobró una especial importancia. Es lo que Peter Burke ha llamado ael descubrimiento del pueblo" ${ }^{1}$; aunque - más bien - se tratara de un "redescubrimiento". En todo caso, esta "nueva ciencia" del folklore nacería con abundancia de paradojas, tal y como algún autor ya ha señalado ${ }^{2}$, y la contradicción entre un enfoque localista y otro universalizador de la misma no iba a ser - precisamente- una de las menores.

De hecho, esta pugna entre formas casi opuestas de entender el folklore algo debió de influir en su estancamiento - como pretendida rama de la antropología - en muchos países europeos. Por un lado, fue visto como una especie de pretexto para la reivindicación de la propia cultura (casi siempre frente a otro $\mathrm{u}$ otros, algo o alguien), dentro de la línea

1 Peter BuRKE, Popular Culture in Early Modern Europe (New york: Harper \& Row Publishers, 1981), pp. 3-13.

2 Honorio VelasCo, “El folklore y sus paradojas”, Reis, 49 (1990), pp. 123-144. 
inaugurada por el alemán Herder — con sus trabajos sobre poesía popular - que tanto habría de pesar en la reconfiguración de ciertos nacionalismos $^{3}$. De otra parte, los ingleses Thoms y Gomme -responsables del acuñamiento y conceptualización del término folklore, como es bien sabido- concederían a éste una significación menos política y más universalista: así, el estudio de la cultura popular no habría de ir - sólo o principalmente- encaminado a la recuperación de un, siempre evanescente, espíritu o "genio nacional"; ése del que - según lo entendieron los primeros folkloristas románticos- los campesinos (como "pueblo" más visible y mayoritario en aquellos momentos en Europa) serían privilegiados herederos y portadores ${ }^{4}$.

El folklore debería contribuir también al conocimiento de la cultura, en su conjunto, y éste fue el enfoque que Antonio Machado y Álvarez - miembro de la Sociedad inglesa de Folklore y fundador de la española- pretendería, sobre todo, difundir en nuestro país. Al menos, inicialmente. Aunque - al igual que en Alemania o Inglaterra - pronto confluyeran y, a veces, llegaran a superponerse aquí ambas líneas de aproximación al folklore en una mezcolanza casi siempre perjudicial. Con el tiempo, esa tendencia germanizante llegaría a influir más que la otra, probablemente por la influencia de un contexto que - desde los movimientos regionalistas y nacionalistas o los mismos impulsos de regeneración política- venía a propiciar el énfasis sobre los conceptos de "cultura" y de "nación" (o "cultura nacional") en el discurso de muchos intelectuales.

Sin embargo, Machado había presentado al folklore como "poderoso auxiliar de la historia y la antropología" 5 dentro del gran edificio que se pretendía construir a partir de los supuestos del evolucionismo cultural, y - siguiendo a Tylor- dejó escrito:

Es, ya, asunto fuera de toda duda que, así como ciertos fósiles son característicos de ciertos terrenos, ciertas concepciones son también exclusivamente propias de ciertos periodos de cultura y que, así como en el mundo animal hay una cadena cuyos eslabones pueden seguirse casi paso a paso, en el mundo de las ideas existe,

3 Véanse, sobre la utilización que Herder y otros muchos tras de él harían del folklore en relación con los nacionalismos, los trabajos de Alain FINKIELKRAUT, La derrota del pensamiento (Barcelona: Anagrama, 1987) y Claude KARNOOUH, "On the Use of Folklore or the Avatars of Folklorism", Communication E Cognition, 17, núm. 273 (1984), pp. 315-335.

4 P. BURKE, op. cit., pp. 15-23.

5 Tomo esta cita de Antonio MACHADO y ÁlVAREZ de su texto programático publicado, primeramente, en El Folk-Lore Andaluz y reproducido más tarde en El Folk-Lore Frexnense, año $1 .^{\circ}$ (1883), p. 3. 
también, una cadena cuyos eslabones podrá señalar la ciencia en día no muy lejano ${ }^{6}$.

No se trata de analizar aquí en qué medida ciertas contradicciones de Machado pudieran influir en el rumbo titubeante que siguió su empresa de implantar y difundir el folklore - como disciplina científica- en España. Por ejemplo, la planificación de una serie de sociedades folklóricas regionales que, pronto, darían muestras - en algunos casos- de una toma de postura nacionalista al margen de la voluntad de su fundador ${ }^{7}$.

O el despróposito de pretender el afianzamiento de esta ciencia reciente fuera del ámbito de las instituciones académicas, convocando para tal proyecto a todo tipo de colaboradores ${ }^{8}$.

Lo que nos interesa, ahora, es la contradicción de Machado dentro de su mismo programa y entre éste y la estrategia de implantación del folklore. Podría decirse, también, que entre sus textos programáticos y la obra posterior. Pues, mientras advierte expresamente que eel carácter de la Sociedad inglesa (de folklore) -a la que él está tomando como modelo- es más científico que nacional" ", llama, por otro lado, a cualquier ciudadano español a participar en esa empresa colectiva de recuperar y conocer la propia cultura popular. Y, aunque había declarado que las sociedades de folklore habrían de procurar el conocimiento del desarrollo del espíritu humano, en general, a través de las diversas capas de cultura por las que ha pasado" ${ }^{10}$, dice también, en sus palabras fundacionales, algo que tiene más que ver con la línea de Herder que con la de Tylor:

Esta Sociedad tiene por objeto recoger, acopiar y publicar todos los conocimientos de nuestro pueblo en los diversos ramos de la ciencia (...) y, en suma, todos

6 Ibid., p. 4.

7 En el caso castellano, por ejemplo, Machado intentó reavivar el interés por los estudios sobre la cultura popular en Castilla —entendiendo como tal a ambas Castillasy, así, conectó con investigadores como Sbarbi. Sin embargo, cuando se crea la "Sociedad de Folk-Lore Castellanon, ésta será presidida por el poeta Nuñez de Arce. La actitud hacia el "plan general" de Machado y la auténtica significación de su figura por parte de los folkloristas de otras regiones aparece bien reflejada en la introducción a los tres volúmenes editados por Joaquín NAvASCuÉs y Francisco Carreras y Candi, Folklore y costumbres de España (Barcelona: Alberto Martín, 1943), 1. ${ }^{a}$ ed. 1931.

8 aNuestra Sociedad —escribe MACHADO en el Folk-Lore Andaluz (1882) - no puede componerse sólo de eruditos y literatos; antes bien, necesita del concurso de todos, y muy especialmente de la gente del pueblo: el ideal de nuestra Sociedad es contar con representantes en todos los pueblecitos y aldeas y, aun a ser posible, en todas las haciendas, cortijos y caseríos".

9 Ibid., p. 4.

10 Ibid., pp. 4-5. 
los elementos constitutivos del genio, del saber y del idioma patrios, contenidos en la tradición oral y en los monumentos escritos, como materiales indispensables para el conocimiento y reconstrucción científica de la historia y de la cultura españolas ${ }^{11}$.

Por supuesto que los problemas para conjugar el conocimiento local con lo universal $\longrightarrow$ con supuestas leyes universales en el funcionamiento de la cultura - no son cosa exclusiva del folklore. Puede afirmarse que sigue siendo éste uno de los temas de fondo que reaparecen en cualquier gran debate antropológico. Si me he detenido - precisamente- en ello es porque creo que, en el caso del folklore, tal conflicto llegó a interiorizarse como parte integrante de la propia disciplina; como motor principal de esa obsesiva práctica recopiladora que conduciría al folklore a desempeñar un papel social -más o menos conscientemente asumidode máquina co-inventora de identidades.

El folklore serviría, fundamentalmente, como archivo fácilmente manipulable desde el que construir $\longrightarrow$ reconstruir- las señas de identidad. Y, todavía, en muchos lugares de Europa sigue sirviendo — casi en exclusiva- para este fin. El problema estudiable se había convertido en factor determinante de lo que estudiaban los estudiosos. Y de cómo habían de estudiarlo. Ya se verá, más adelante, por qué me he centrado en esta contradicción y no en otras de las muchas paradojas que han venido condicionando la historia del folklore. Asuntos de los que, por otra parte, sí me he ocupado en anteriores trabajos ${ }^{12}$.

Me he basado en textos de Machado para mostrar tal contradicción por haber sido él uno de los principales introductores - no el únicode esa nueva aproximación a la cultura popular (que se rebautizó como folklore) en España. Pero podría haber tomado como ejemplo a libros escritos recientemente en los que se dicen - poco más o menos- las mismas cosas y, en los cuales, sus autores siguen incurriendo en parecidas contradicciones. Quizá este fenómeno de "declaraciones programáticas" tan reiterativas, que - a veces- proyecta la impresión de una perpetua refundación del folklore en nuestro país, tenga mucho que ver con la íntima conexión entre la construcción de las identidades y determinada tradición folklórica. Ese tipo de folklore -el que se presenta como empresa de concienciación regional o nacional- habría renacido en tantas

11 A. MACHADO Y ÁlVAREZ, "El Folk-Lore Español. Sociedad para la recopilación y estudio del saber y de las tradiciones populares. Bases", El Folk-Lore Andaluz (1882), p. 501.

12 Véase, especialmente, Luis DíAZ VIANA, "Folklore", Diccionario temático de antropologia, Coord. Angel AGUIRRE (Barcelona: Boixareau Universitaria, 1993), pp. 333-338. 
ocasiones como las propias identidades a cuyo servicio estaba. Se habría reinventado casi constantemente.

De cualquier modo, unos y otros folkloristas europeos coincidían - por lo general-, inicialmente, en identificar el concepto de folklore con una "cultura del pueblo" que era sólo la de los campesinos y, algo más tarde, en colocarla dentro de un estrato - remoto y estancado- de la supuesta evolución cultural de toda la humanidad. Se zurcían, así, paños de muy distinto origen en una curiosa túnica que nada más resultaba brillante e inconsutil en apariencia: la cultura popular equivalía a cultura campesina, que - a su vez- constituiría un estadio "primitivo" y atrasado dentro de la historia cultural, pero - por otro lado- se perseguía rescatar (entre los vestigios de esa etapa perdida) los rasgos de identificación de cada pueblo, su auténtico "genio colectivo".

Se trataba, pues, de estudiar (o, más bien, recoger) la cultura de los campesinos en cuanto a "salvajes de aquín o "de la puerta de al lado". Y se recopiló -más que se estudió- esa cultura popular campesina como cosa independiente, casi siempre a partir de sus productos descontextualizados, porque así se escamoteaba la muy ardua tarea de estudiar a "los otros de dentro" y se favorecía el posterior uso de tales materiales en su dimensión de signos de identidad.

La etnología colonial de aquella época —que se ocupó de recopilar datos (a menudo, indirectos) sobre los "salvajes de lejos" - quedaba, de esta manera, complementada por la visión -igualmente exotista- que el folklore venía a proporcionarnos acerca de "los salvajes del interior ${ }^{13}$.

\section{Cultura, Civilizacion y SOCIEDAD}

La consecuencia de todo lo expuesto más arriba ha sido que los términos y conceptos básicos sobre lo popular, lo tradicional o el folklore quedaron, por mucho tiempo, anclados entre las coordenadas de lo que era una discusión teórica propia de la segunda mitad del siglo XIX: la reivindicación romántica de la "cultura del pueblo" como la más auténticamente propia y defendible, por una parte; y, de otra, la inclusión del conocimiento de las distintas "culturas populares" en el proyecto de edificio - separado en varias plantas- que el evolucionismo cultural pretendía reconstruir sobre lo que, pretendidamente, habría sido la historia de la cultura humana.

13 L. DÍAZ VIANA, "Cultura rural y cultura urbana. Alegorías etnográficas de la tradición y el progreso", Viva San Martín (Madrid: Ministerio de Agricultura, 1990), pp. 11-27. 
Tales términos y conceptos pasaron, además, a la antropología, siendo utilizados por sus practicantes menos rigurosos sin la necesaria reflexión; pues el debate que, a partir de entonces, se produciría en torno al mismo concepto de cultura hubiera exigido una revisión actualizadora de todo el repertorio terminológico empleado, corrientemente, a propósito del folklore. $\mathrm{Y}$ es que las tradiciones folklórica y antropológica, en un principio complementarias, devinieron con el tiempo —en varios países de Europa- en disciplinas distanciadas cuyos oficiantes trabajaban de espaldas, si no se miraban con recelo.

Mientras, se había consumado también la separación -cuando no el ocultamiento- de unas realidades íntimamente ligadas entre sí y cuya visión de conjunto resultaba muy importante tanto para la historia como para la antropología: me estoy refiriendo a la existencia incontestable de una diversidad de vías - y tradiciones- dentro del conglomerado de construcciones humanas que llamamos cultura. Una existencia que - sin embargo- fue sistemáticamente parcelada, de modo que la reconstrucción del "devenir histórico" de Occidente no podría efectuarse, ya, más que de una forma también parcial.

En las últimas décadas, se ha reflexionado mucho -desde la antropología y la historia - sobre esa división artificiosa y hemos intentado corregir la utilización rotunda y simplista de dicotomías como la de cultura popular / cultura de élite o cultura folklórica / cultura erudita. No obstante, se siguen empleando - a menudo- tales términos como si se tratara de realidades completas en sí mismas y, prácticamente, contrapuestas.

Es, por tanto, a partir del análisis del propio concepto de cultura -y de las transformaciones que el mismo ha ido experimentando a lo largo de este siglo- que habremos de volver a afrontar los problemas que se ocultan tras esa etiqueta de "cultura popular". Pues, aunque nos haya resultado más confortable hacerlo así, no podemos continuar considerando a lo popular como un aspecto marginal de nuestras disciplinas. $\mathrm{Ni}$ como algo aislado del resto de la historia y de la cultura, cuando constituye una parte central para su verdadera comprensión. Este falseamiento nos impediría comprender demasiados procesos fundamantales en lo que han sido, son y hacen los seres humanos. Y no sólo en Occidente.

Se ha querido ver en el folklore - como manifestación de la cultura popular - la reliquia de un orden pasado (o de una manera "tradicional" de entender la vida) ya en trance de desaparición que, además, sólo existiría como tal en las sociedades postindustriales ${ }^{14}$. Sólo en ellas se

14 Esta es, en líneas generales, la postura defendida por George FOSTER, "What is Folk Culture?», American Antbropology, 55 (1953), pp. 159-178. 
habría producido ese fenómeno de remanencia de unos modos y costumbres "tradicionales" en cohabitación y contraste con el modelo de sociedad que habría traído la revolución industrial.

Sin embargo, si vamos al problema de fondo que se esconde tras las estrategias intelectuales en que siempre ha estado envuelto el folklore, podremos comprobar que el asunto fundamental es otro: la tensión entre las distintas tradiciones y modelos que componen cada cultura. Pues en todas las culturas hay conocimientos que sólo son conocidos por una élite - grupo o grupos más dominantes o decisivos- y que se transmiten o difunden (a veces, se guardan - precisamente- en secreto como garantía de poder) de distinta manera a aquellos saberes más ampliamente compartidos por la comunidad. En este sentido, no el fenómeno del folklore como ha sido caracterizado en Europa - y desde Europa- pero sí el de la coexistencia y, con frecuencia, pugna entre distintas tradiciones culturales dentro de cada cultura no sería específico del mundo occidental ni podría explicarse, únicamente, en razón de determinadas transformaciones económicas que se han producido en él durante épocas recientes.

Se trataría de un fenómeno mucho más amplio que habría tenido en cada cultura su propia historia, su particular manera de ir resolviendo ese juego de tensiones entre diversas influencias culturales en relación con el poder.

Por otra parte, no debemos responsabilizar al folklore o a los folkloristas -en exclusiva - de que la cultura popular haya sido concebida como fenómeno separado (y hasta aislado) de los otros modelos de aprendizaje y transmisión de la cultura; como una isla atemporal casi ajena a la historia de Occidente. Tal situación probablemente fue favorecida por el hecho de que cierta clase de antropólogos se fuera adentrando por derroteros más bien ahistoricistas, mientras determinados historiadores se habían ocupado - por mucho tiempo- sólo de la historia de los grandes hechos, los grandes hombres y las grandes obras.

En época reciente, sin embargo, se han escuchado voces - tanto de antropólogos como de historiadores- llamando al diálogo y al encuentro entre estas dos disciplinas ${ }^{15}$. Y aunque no cabe duda de las muchas dificultades y riesgos que la interdisciplinariedad - $\tan$ deseable en teoríapresenta, también es cierto que ya se ha avanzado algo (aunque aún sea muy poco) en el camino de la colaboración entre historiadores y antropólogos: al fin se observan, leen y escuchan los unos a los otros. En algunos casos, al menos.

15 En este sentido, han aportado significativas contribuciones a ese -aún decepcionante- diálogo historiadores como Georges Duby o antropólogos como Clifford Geertz. 
Pues, a pesar de que la existencia de una jerga, una tradición científica y unos enfoques metodológicos diversos no favorecen -en muchas ocasiones- ese entendimiento, el estar coincidiendo - tan a menudo- sobre temas y problemas que son comunes a los profesionales de la historia y la antropología, hace cada vez más obligada entre ellos tal aproximación.

Una de esas temáticas coincidentes, un problema que afecta por igual a los trabajos de antropólogos e historiadores es - precisamente- el de la revisión y análisis de lo que se ha venido llamando "cultura popular". Durante siglos, como ya he recordado, pareció que el estudio de la cultura habría de consistir - para buena parte de los historiadores- en un mejor conocimiento de las "grandes civilizaciones". De otro lado, antropólogos como Tylor no hacían tampoco una distinción demasiado precisa entre los conceptos de cultura y civilización, quizá porque desde una visión evolucionista de lo cultural esa diferencia sobraba.

Toda "cultura" tendería a pasar por unas mismas fases hasta llegar a los más altos grados de "civilización". No obstante, Tylor reconocía que "el progreso, la degradación, la supervivencia, el reconocimiento, la modificación, todos ellos son modos de la conexión que mantiene unida la compleja red de la civilización" ${ }^{16}$. Si bien, lo importante era que "a pesar de la continua interferencia de la degeneración, la principal tendencia de la cultura desde los orígenes a los tiempos modernos ha sido del salvajismo a la civilización" ${ }^{17}$.

Tylor concebía, sobre todo, el estudio de la cultura en cuanto a historia de la humanidad y, más exactamente, como "historia de los orígenes". Una historia, además, que - según sus propias palabras "comenzaba -en la época en que él vivió- a ponerse a nuestro alcance" ${ }^{18}$. Citando a Comte, explicaba que "ninguna concepción puede entenderse excepto a través de su historia" ${ }^{19}$. Y aplicaba este principio a la idea de cultura.

Malinowski, que en tantas cuestiones diferiría de los planteamientos de Tylor, no se alejó — sin embargo- demasiado de éste al hablar de "civilización", pues caracterizaba a la misma como "un aspecto especial de las culturas más avanzadas” ${ }^{20}$. Desde entonces, puede decirse que casi cada gran corriente antropológica ha aportado algún nuevo rasgo al concepto de cultura y variado —en cierto modo- nuestra visión al respecto.

16 Edward W. TYLOR, "La ciencia de la cultura" (1871), El concepto de cultura. Textos fundamentales, Comp. J. S. KHAN (Barcelona: Anagrama, 1975), p. 40.

17 Ibid., p. 43.

18 Ibid., p. 46.

19 Ibid., p. 42.

20 Bronislaw MALINOWSKI, "La cultura", ibid., p. 85. 
Tras Tylor, las aproximaciones de Malinowski - por un lado- y de Boas - por otro- (aun diferentes en muchas cosas, también, como es sabido) van a venir a coincidir en un giro fundamental: la distición antropológica dentro de la cultura no se establecerá, ya, entre los estadios más o menos elevados de ella - Tylor hablaba aún de "razas inferiores" $^{21}$-, sino entre la cultura de unas sociedades y de otras. El criterio, pues, para contrastar las culturas pasa a ser más espacial que temporal, distanciándose -en definitiva - de la historia.

Las diferencias entre los conceptos de sociedad y cultura tampoco aparecerán demasiado claras, desde este momento, si bien las diversas escuelas pondrán más su énfasis en el estudio de lo social o de lo cultural de acuerdo con sus propios intereses. Va a ser Kroeber, discípulo de Boas, quien mezclando, a menudo, los conceptos de "cultura "y"civilización" terminará reafirmando la conexión de cultura y sociedad -0 , mejor, de cada sociedad y cultura entre sí-. Pero Kroeber añadirá, todavía, un nuevo rasgo al concepto de cultura: al igual que Malinowski concebirá a ésta como "herencia social" ${ }^{22}$, aunque - a diferencia de él- no entenderá sólo a la cultura en cuanto a "necesidad social" ${ }^{23}$, sino como algo que trasciende lo social.

La cultura - para Kroeber- además de ser una representación y agente conformador de cada sociedad superaría, incluso, la vieja oposición entre lo físico y lo espiritual. Pertenecería al nivel de lo que él denominaba "Superorgánico" y no supondría un "paso" (como lo social) en el camino de la humanidad; más bien un salto a otro plano ${ }^{24}$ :

El proceso de la civilización es claramente de acumulación (...) La distinción primordial entre el animal y el hombre no es la mental y la física, que es de origen relativo, como la de lo orgánico y lo social, que es cualitativa. La bestia tiene mentalidad y nosotros tenemos cuerpo, pero en la civilización el hombre tiene algo de lo que la bestia carece ${ }^{25}$.

Ese algo - la "civilización" que, en Kroeber, sigue equivaliendo a "culturan - se acumula, se transmite y aprende sin producir (de distinta manera a lo que, según las tesis evolucionistas, habría ocurrido con los ani-

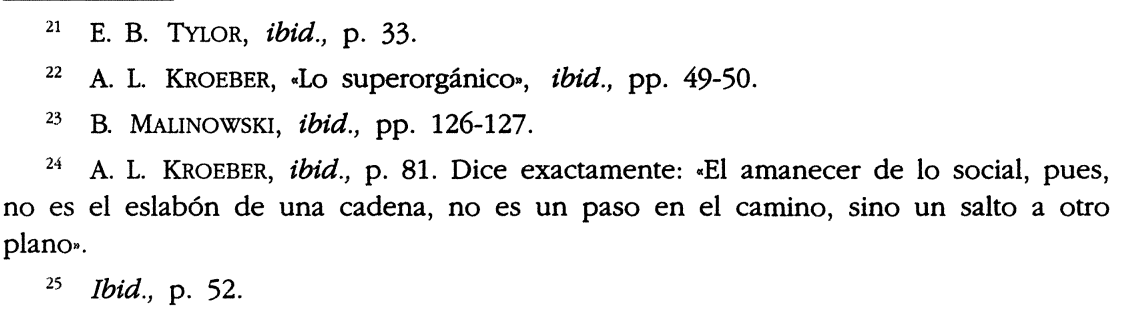


males) "cambio biológico alguno". En la medida en que lo cultural se imbrica en lo social - de acuerdo con el propio Kroeber-, aunque no se limite a ello, resulta al menos discutible considerar a la cultura como totalmente "superorgánica" (en el sentido de "no biológican) cuando no resulta aún del todo claro si la tendencia a la sociabilidad en los seres humanos es herencia de la biología o no.

En efecto, otros animales viven -y se organizan - en grupo (independientemente de que les podamos considerar "sociables" o "sociales", pues eso depende, sobre todo, del sentido que demos a estas palabras), pero - como señalaba Kroeber- los hombres hemos elaborado, además, una herencia acumulativa y transmisible que otros animales no tienen: la "cultura" -más que la "civilización", aunque Kroeber utilizase casi indistintamente ambos términos—. Los lobos, por ejemplo, podrán ser "sociables" o sociales"; nunca "cultos".

La cultura así entendida se transmite y aprende en grupo —en pequeños grupos- Es lo "micro" o local ${ }^{26}$ respecto a lo "macro" o general: lo específico de un conjunto de hombres respecto a los comportamientos generales de la sociedad humana. Desde esta perspectiva, quizá convenga rescatar la palabra "civilización" para designar aquellos aspectos más globales de la cultura que tienden a ser codificados de forma estable y manejados como abstracciones. En suma, puede que nos interese hablar de "civilizaciones" para referirnos a lo que Redfield ${ }^{27}$ denominó "Gran Tradición", pues de hecho esa es la parte de la cultura que ha sido identificada con "lo civilizado"; que se ha superpuesto o invadido otras culturas abarcando amplias épocas y espacios.

La "Pequeña Tradición" pasaría, entonces, a identificarse con esa cultura "micro", local y de grupo: con la cultura en sí. (Aunque, entre los "cultos", cultura haya sido, precisamente, por mucho tiempo la otra $-\mathrm{y}$ con mayúsculas-). Esta simple recalificación volvería casi innecesario que continuáramos hablando de cosas como "cultura popular" o "folklore".

Se trataría, en realidad, de un problema de niveles o, si se prefiere, de escalas. No de qué elementos se combinan, sino - al igual que sucede en una pintura- de cómo (en qué tamaño y tonos) se combinan esos elementos. De qué manera se conjugan unos colores y en qué proporciones.

Creo que resulta especialmente lúcida la conexión que Roman Jakobson estableció entre lengua-cultura (diríamos, de acuerdo con la revisión anterior, "civilización" o "Gran Tradición") y folklore, o "cultura popular"-ha-

26 C. GEERTZ, Local Knowledge (New York: Basic Books, Inc., 1983), p. 167.

27 Robert REDFIELD, The Little Community and Peasant Society and Culture (Chicago: The University of Chicago Press, 1960), 1. ${ }^{\mathrm{a}}$ ed. 1956. 
bla ${ }^{28}$. Basándome libremente en la misma he configurado el siguiente cuadro en el que las adscripciones de la antropología e historia a uno u otro lugar indican, sólo, lo que estas disciplinas han sido $\multimap$ a lo que mayoritariamente sus practicantes se han dedicado- y no lo que, a la fuerza, habrán de ser. El término sociedad es usado aquí en su sentido de "conjunto de grupos o familias asociadas con carácter estable" y por ello aparece ligado -como lo estuvo ya desde los romanos- a los vocablos "civis" y "civilización" :

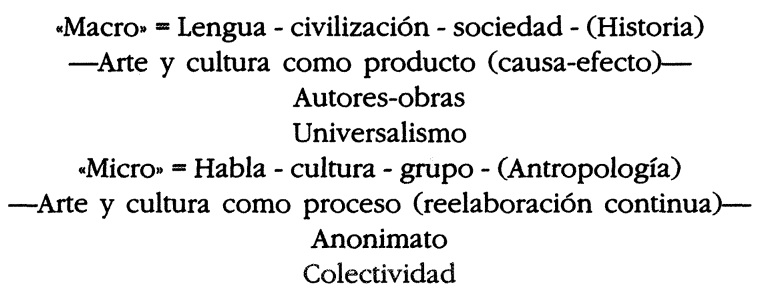

Dentro de cada "cultura-civilización" caben muchas "culturas-micro". Pero los antropólogos, como certeramente señaló Goodenough, "raramente han considerado los simples conglomerados en cuanto a unidades de lo que llamamos culturan ${ }^{29}$.

$Y$ esas unidades existen. En cada una de esas unidades un microcrosmos resume el funcionamiento de lo que la cultura es. Hoy -como ayer - resulta perfectamente posible que, en cualquier sociedad, un individuo pertenezca a más de un grupo de cultura común, sea competente en más de un conjunto de conocimientos o de normas y utilice uno $\mathrm{u}$ otro "registro" cultural (por emplear un término muy esclarecedor que procede de la lingüística) según convenga a cada situación.

Ahora - más que en otros tiempos- esa polivalencia (que antaño fue de oficios) se traduce en términos espaciales. Ya no se es noble, intelectual y guerrero a la vez, pero sí se come o se habla de muy diversas formas - a la "americana" y "standarizadamente" o a lo castizo y según la jerga local- dependiendo de cada contexto. Y, de igual modo, se escucha un tipo u otro de música o se lee una u otra literatura. $\mathrm{O}$, simplemente, se oye la radio y se ve la televisión. Todos participamos de una "civilización" y vivimos de acuerdo con el código de una o - más bien-varias culturas.

28 Roman JAKOBSON y P. BOGATTYRE, "Die Folklore als Besondere Form des Schaffens", Verzameling van Opstellen Door Oud-Leerlingen en Bevriende Vakgenooten Opgedragen Aan Mrg. Prof. Jos. Schrijnen (Nijmegen-Utrrecht, 1929), pp. 900-913.

29 Ward H. GoOdenOUGH, "Cultura, lenguaje y sociedad", El concepto de cultura..., p. 231 
Que no se entienda, por lo tanto, el uso del término "civilización" en el sentido de un grado superior de cultura, sino simplemente en algo paralelo a lo que es la lengua para el habla: un nivel de abstracción y el reconocimiento -e incluso fijación- del sistema sobre el que se basan los distintos hechos de habla, es decir, su gramática.

\title{
3. LA REVISIÓN DEL CONCEPTO DE CULTURA POPULAR EN LA ANTROPOLOGÍA Y LA HISTORIA
}

\begin{abstract}
El nombre de paganos deriva de las aldeas atenienses en donde tuvieron sus comienzos. En aquellos lugares agrestes y en aquellos pagos establecieron los gentiles bosques sagrados y erigieron ídolos. Por ser tal su origen, recibieron este nombre los paganos.
\end{abstract}

SAN ISIDORO DE SEVILLA, Etimologías (Madrid, 1982); versión española José Oroz Reta.

Kroeber toma de Herodoto una anécdota bastante apócrifa —como él mismo reconoce- que, en su opinión, viene a demostrar la no existencia de un "lenguaje humano natural y, por tanto orgánicon; es decir, el carácter cultural y superorgánico del mismo:

\begin{abstract}
Herodoto habla de un rey egipcio que, deseando poner en claro (cuál habría sido) la lengua materna de la humanidad, hizo que se aislara a algunos niños de los de su especie, teniendo sólo cabras por compañía y sostenimiento. Cuando los niños se hicieron mayores y fueron visitados (por el monarca) gritaban la palabra "bekos" o, sustrayendo la desinencia que el sensible y normalizador griego no podía omotir para nada que pasara por sus labios, más probablemente abek" Entonces el rey envió a gentes a todos los países para ver en qué tierra significaba algo este vocablo. Supo que en la lengua frigia significaba "pan" y, suponiendo que los niños gritaban pidiendo comida, sacó la conclusión de que hablaban frigio al pronunciar su lenguaje humano "natural" y que, por lo tanto, esta lengua debía (de) ser la original de la humanidad. La creencia del rey en un lenguaje inherente y congénito del hombre, que sólo los ciegos accidentes del tiempo habían distorsionado en una multitud de lenguas, puede parecer simple; pero, en su misma ingenuidad, la investigación revelaría la existencia de multitud de personas civilizadas que todavía se adhieren a ella ${ }^{30}$.
\end{abstract}

A Kroeber le preocupaba sobre todo desmontar cierta creencia - pretendidamente científica - en que lo cultural estaría obligadamente determinado por lo biológico. Y así aclaraba — precisando, de paso, el signifi-

30 A. L. KROEBER, ibid., pp. 55-56. 
cado que para él tenía la palabra "civilización" - que muchos estudiosos de la ciencia seguían con pretensiones semejantes a las del rey egipcio de la anécdota de Herodoto: "El estudiante actual que ve el entendimiento moldeado por la civilización del hombre en la mentalidad del perro o del mono, o que trata de explicar la civilización —es decir, la historiapor medio de factores orgánicos, comete un error que es menos anticuado y está más de moda, pero que es de la misma clase y naturaleza" ${ }^{31}$.

En lo que atañe a los problemas que he venido tratando, lo interesante de la historieta, sin embargo, empieza donde los relatos de Kroeber y Herodoto parecen terminar: ¿Que ocurrió después —caso de que la anécdota fuera auténtica- con aquellos niños que balaban como "cabras frigias"? ¿Permanecerían chillando "bek" - como sus primeras instructoras y compañeras- por las galerías de palacio durante años y años hasta su muerte? ¿O llegarían a ser instruidos por maestros con más recursos hasta hablar - y quizá escribir - en egipcio con perfección como gentes de la alta realeza?

Imaginemos que los muchachos eran tres y no dos: que uno de ellos, en efecto, permaneció en palacio. El rey necesitaba su presencia para demostrar - a quien tuviera curiosidad por ello- la autenticidad de una prueba llevada a cabo "científicamente". De modo que, aunque el niño viviera en la corte, no recibió la educación propia de la familia real, pues la razón de su vida - y de su estancia palaciega - era gritar "bek" a todo aquel que quisiera oírlo. Y cuentan que así lo hizo hasta el fin de sus días, si bien - al cabo de unos cuantos años- los visitantes del monarca fueron perdiendo el interés por los resultados de aquel experimento que, en su momento, despertó una enorme expectación entre las clases más cultas. No obstante, el chico - que como todas las cabras y todos los hombres fue envejeciendo con el tiempo- quedó en el inmenso palacio del mismo modo que, en todas las administraciones gigantescas, permanecen olvidados en un rincón documentos, objetos o, incluso, personas.

"Bek" — que de esa manera le llamaban todos- siguió el destino de los animales exóticos que pasan de moda, de los perros que se hacen mayores o de los guardias y bedeles que cumplieron alguna vez una función pero que, después, se llenan de telarañas en las esquinas de edificios destartalados. Mientras, "Bek" hizo sus primeros amigos entre los siervos de palacio que se hallaban más cerca de las bestias, pues él siempre deambuló tristemente en ese confuso estadio que los más inteligentes y poderosos le habían asignado: medio animal y medio hombre, curiosidad doméstica que, al hacerse cotidiana, pierde su condición de cosa ex-

$31 \quad$ Ibid., pp. 56-57. 
traordinaria. Y aprendió algunas palabras que casi se guardó para sí y para sus escasos compañeros de borracheras y juegos pues nadie esperaba de él más que el grito de abekn y otros sonidos ininteligibles.

Supongamos, ahora, que el segundo de los muchachos fue recogido por un humilde servidor de palacio - una vez el rey se desinteresó de los "conejillos" de su experimento-; que éste pudo haber sido - a pesar de su conexión con la corte- algún artesano más bien marginal: un curtidor de pieles o un teñidor de túnicas, pero alguien que -en todo caso- tuviera que vivir en barrios apartados (semi-agrestes y semi-rurales de la ciudad) en razón del tipo de locales que necesitaría para la realización de su trabajo. Tarea maloliente e incómoda para los vecinos. Todo ello condicionaría la vida de "Bekos" —que así podemos llamar al joven para diferenciarlo del anterior-, haciendo pronto del chico uno de tantos "obreros de suburbion; un personaje anónimo que pasaría - ya- su existencia exactamente igual (día tras día), rodeado de otros como él que habrían venido de los campos circundantes y aún mantendrían las costumbres y conocimientos de sus anteriores oficios; la agricultura, la pesca, el pastoreo.

El último de los niños vivió siempre como un hombre sin nombre. Uno de los generales del rey decidió llevarlo a su villa campestre en donde -más por comodidad organizativa que por afecto de sus protectores- el muchacho sería educado casi como un hijo de la familia. Hacía grupo, pero "no" era del grupo. Nunca podría serlo. Supongamos - para seguir suponiendo- que la historia que he inventado (de una manera intencionadamente ambigua en lo que toca a espacio y tiempo) no transcurría en tiempos de Herodoto sino bajo el romano imperio y que, por ello, el joven -aunque egipcio- tuviera que aprender, al ser educado con sus compañeros de élite, latín y griego. Imaginemos, para acabar, que su crisis de identidad y el hecho de haberse acostumbrado a una vida material e intelectualmente confortable fueran factores que, por fin, le indujeron a refugiarse en la tranquilidad de los "conventos": entonces no los había como tales, así que - - en el escaso contexto histórico de que hemos rodeado al personaje- bastaría con que éste se incorporase, por ejemplo, a algún grupúsculo casi monacal desgajado de la escuela pitagórica. Eso le pondría en contacto - en pleno campo- con una de las tradiciones intelectuales que se reclamaban más refinadas y antiguas. A un tiempo universalista y secreta.

La vida de "Bek" fue recogida, al dictado, de sus propios labios por un escriba de la corte que enderezó el estilo oral -algo deficiente- de cabra "tan distinguidan. De las vidas de "Bekos" y el hombre sin nombre no nos ha quedado testimonio escrito, si bien se atribuye a este último una intrincada disertación sobre el lenguaje de los animales que, según autores nada fiables, pudo formar parte - alguna vez- de los "Versos de oro" pitagóricos. 
Relatos parecidos a éstos podrían inventarse —con los mismos personajes- para distintas épocas. Es más: animo a quienes me estén siguiendo a que lo hagan para comprobar, entre otras cosas, si estos casos paradójicos serían reproducibles en cualquier lugar y tiempo. Yo creo que, con matices, sí; al menos, dentro de lo que - vagamente- llamamos "tradición occidental. Y - como habrá deducido cualquiera que me lea- la controversia algo disparatada que he buscado, dentro de estas "historias de vidan totalmente fictias, con algunas de las dicotomías que más usamos en cultura (por ejemplo, élite/pueblo, rural/urbano o escrito/oral) no es, por supuesto, una casualidad.

¿Qué pretendo con tales parábolas no exentas de humor que a más de uno le resultarán - quizá - irreverentes, pero que — sin embargo- me han ayudado a expresar (mediante esa licencia parabólica) algo que en otro tipo de lenguaje resultaría muy difícil de decir? Desde luego, intento poner de manifiesto la gran contradicción y burda simpleza de ciertos tópicos que siguen siendo utilizados habitualmente en el mundo de la etnografía. Pero, sobre todo, me interesa que -desde estas trampas que he elaborado para desenmascarar simplismos- podamos reflexionar en torno al concepto de "cultura popular" con plena consciencia de su complejidad y de su importancia dentro del debate más amplio que sobre la propia idea de cultura deberíamos mantener historiadores y antropólogos.

Por lo común, la discusión sobre la "cultura popular" se ha centrado más en el desglose de los posibles significados del término "popular" - siempre remitiéndonos a "pueblo" - que del vocablo "cultura". Y, sin embargo, el verdadero problema está en el sentido que demos a este último. Es más, desde la visión más comprensiva y global del término cultura, la polémica sobre lo popular o no popular puede resultar casi innecesaria.

Dejo para otro lugar - $-\mathrm{y}$, si es posible, otros autores- el farragoso recuento etimológico de los significados que, a lo largo del tiempo, se han adjudicado a "cultura" y "pueblo". Es el acercamiento a una concepción totalizadora de cultura en sus distintas unidades y vías lo que más ha de preocuparnos ahora, pues sólo desde ella avanzaremos (como adevertía al principio) en un análisis verdaderamente integrador de la historia humana.

Con el término "popular" se ha pensado que nos referíamos a "pueblo", cuando, en realidad, estábamos aludiendo - fundamentalmente- a una de las formas de manifestación cultural que caben dentro del concepto de cultura.

Así, se intentó identificar lo popular con un "pueblo" que, en su polisemia desbordante, podía ser entendido como: 
- El pueblo-nación de los románticos nacionalistas

- El pueblo solamente campesino de los folkloristas primeros

- El pueblo-clase o clases dominadas de los pensadores marxistas

- El pueblo masa subalterna tal como parece ser entendido por algunos sociólogos.

Y lo popular, también, como un estilo de literatura o de arte. Una manera de crear y transmitir cultura. Este enfoque, que ha sido practicado - desde antiguo- por algunos estudiosos de la tradición folklórica vuelve a entroncar con la revisión del problema de la cultura popular que antes apunté: cuando retomando unas palabras de Goodenough señalaba que la cultura debería ser vista como un conjunto fragmentario de conglomerados y unidades; y que lo que hemos venido llamando "popular" responde, precisamente, a uno de esos conglomerados, a una de las formas de invención y transmisión de la cultura ${ }^{32}$.

Podemos considerar que el pueblo somos todos y no sólo los campesinos o las clases dominadas: "¿Who are the people? We aren -Escribió Alan Dundes ${ }^{33}$. Que actuamos "popularmente" en tal o cual momento independientemente de que seamos "pueblo" o no, pues como ha señalado - de forma muy certera- Peter Burke las élites europeas han sido, por lo general, biculturales y bilingües ${ }^{34}$. Que la oposición entre los términos de "popular" y "culto" constituye una dicotomía simplificada $-\mathrm{y}$ casi caricaturescadentro de la cual hacemos encajar, a la fuerza, el complejo entramado de estadios y vertientes a traves de los cuales funciona la cultura. Que es, precisamente, en las obras de ámbito "culto" o "erudito" donde -en determinadas épocas - la cultura popular se nos presenta más coherente, tal y como nos ha mostrado Mijail Bajtin en sus estudios sobre el mundo de Rabelais ${ }^{35}$. Que las "tradiciones" de esa cultura popular a menudo son una invención - reinvención - de las élites, según señalara Eric Hobsbawm ${ }^{36}$.

Ya entendamos lo "culto" y "lo popular" en cuanto a Gran y Pequeña Tradición - de acuerdo con la denominación acuñada por Robert Redfield ${ }^{37}$ - que, como extremos de una línea continua se conectaran e

32 Ibid., pp. 232-233.

33 Alan DunDES, «Who Are the Folk?", Frontiers of Folklore, Ed. William R. BASCOM (Boulder, Colorado: Westview Press, 1977), pp. 19-20.

34 P. BURKE, op. cit., pp. 58-64.

35 Mijail BAJTIN, La cultura popular en la edad Media y en el Renacimiento (Madrid: Alianza editorial, 1987).

36 Eric HOBSBAwM y T. RANGER, The Invention of tradition (Cambridge: Cambridge University Press, 1983).

37 R. REDFIELD, op. cit. 
interinfluyeran mutuamente. Ya los veamos como un juego de tensiones entre "centro" y "periferia", a la manera que ha ensayado William Christian en su aproximación al fenómeno de la religiosidad popular en España ${ }^{38}$.

En todo caso, hay importantes realidades que aún se nos escapan a la hora de acercarnos a la llamada "cultura popular". Y es que no deberíamos de seguir simplificando $\longrightarrow$ reduciendo- todos aquellos aspectos que crean algún problema para su estudio, sino profundizar, al fin, en esos problemas; enfrentarnos con el mismo conflicto. Pues ipor qué resulta tan complicado estudiar la cultura popular e -incluso- definirla o denominarla?

Porque, en primer lugar, la cultura de una sociedad concreta no es un "todo" sin fisuras como algunos han preferido suponer. Tanto si hablamos de "cultura popular", o "tradicional" —que remite (en su misma distinción) a una de las estrategias que han desarrollado los "cultos" para mejor asimilar lo que les interesaba del "pueblo" ${ }^{39}$-, como de "cultura folklórica", estaremos empleando términos diversos para designar lo mismo: un mundo que sigue siendo presentado como opuesto al de la "cultura de élite" —mejor, de élites_, "erudita" o "hegemónica". Y, sin embargo, unas y otras formas de cultura constituyen partes inseparables - pero diferenciadasde ese "todo".

En segundo lugar, lo "popular" no debe ser visto más como una "sustancia", como un contenido inalterable, sino como un estado - y estadiode cultura con unas vías de transmisión y aprendizaje características que contribuyen, además, a caracterizar lo transmitido en cuanto a "cultura popular". Una materia "X" es codificada como "no culta" - porque es lo "culto" lo que se debería describir, quizá, con más precisión-; quiere decirse, de cualquier modo, que es el formato, el vehículo (ya se trate de "pliegos de cordel" o de "folletines sentimentales"), la confusión entre lo oral y lo escrito, lo que advierte del tipo de cultura que se nos está sirviendo.

En tercer lugar, y como apuntaron Passeron y Grignon ${ }^{40}$, las tensiones y transformaciones en el campo de la cultura, el juego entre sus distintas tradiciones, no puede - ni debe- aislarse de las relaciones de po-

38 William A. CHRISTIAN, Moving Crucifixes in Modern Spain (Princeton: Princeton University Press, 1992) y, en general, todas sus otras obras sobre religiosidad popular en España. Apariciones en Castilla y León. Siglos XVI y XVII (Madrid: Nerea, 1990).

39 Véase mi apreciación al respecto en las páginas introductorias de Palabras para vender y cantar. Literatura popular en la Castilla de este siglo (Valladolid: Ámbito, 1987).

40 Claude GRIGNON y J. C. PASSERON, Lo culto y lo popular. Miserabilismo y populismo en sociología y literatura (Madrid: Ediciones de la Piqueta, 1992). 
der entre grupos. El conocimiento mismo - concepto básico que subyace bajo el de cultura- es, de acuerdo Con Foucault, auna cierta relación estratégica en la que el hombre está situado" ${ }^{41}$.

La "cultura popular", artificiosamente caracterizada como "oral", "rural" y "antigua" $\longrightarrow$ o supervivencia de fases culturales pasadas - por la mayoría de los folkloristas europeos desde el siglo XIX, no puede ser - ya- más entendida como sustancia quieta o mundo cerrado; sí como una especial manera - entre otras muchas- en que el conjunto de conocimientos que llamamos cultura viven, giran y se propagan. Esa sería, posiblemente, la figura adecuada: las culturas se asemejan más a una rueda —o círculos superpuestosque giran y generan, con ello, invenciones de toda clase, que a un cuadrado estático como el que trazaron Passeron y Grignon ${ }^{42}$.

Esquema 1

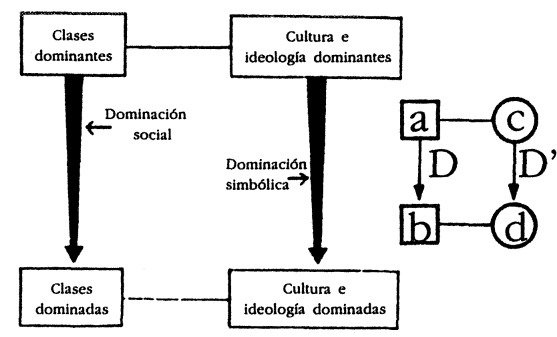

Esquema 2

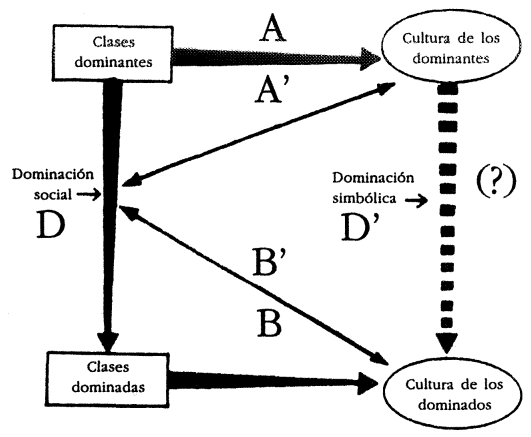

Claude Grignon -Jean-Claude Passeron

En esos círculos comunes van rotando las diversas "unidades", las distintas "tradiciones" de cultura, y pasando de uno a otro triángulo según el modelo cultural de sociedad que las élites y demás grupos van imponiendo en cada momento. De modo que el problema del estudio de la cultura es también -0 , sobre todo- un problema histórico. Como parece querer dar a entender Clifford Geertz cuando dice:

El concepto de cultura al cual me adhiero... denota una norma de significados transmitidos históricamente... un sistema de concepciones heredadas y expresadas en formas simbólicas por medio de las cuales los hombres se comunican perpetúan y desarrollan su conocimiento de la vida ${ }^{43}$.

41 Michael FouCAULT, La verdad y las formas jurídicas (Barcelona: Gedisa, 1995) p. 30.

42 C. Grignon y J. C. PASSERon, op. cit., pp. 28-31.

43 C. GEERTZ, The Interpretation of Culture (New York: Basic Books Inc., 1973), p. 89. 
No podemos estudiar la historia sin prestar atención a ese conjunto de comglomerados que, en cada época, han configurado la realidad cultural de una sociedad; y no deberíamos estudiar la cultura como si la percibiéramos desde un "presente etnográfico" inamovible, sino en su historia. Más allá de los debates entre la historia llamada "intelectual" y la denominada de las "mentalidades" lo que importa es ir completando - desde cualquiera de esos enfoques - nuestra visión de los seres humanos en el espacio y en el tiempo.

Según hizo notar D. Julio Caro Baroja, se ha tendido a estudiar la "Cultura popular" como cosa ligada a la "tradición" y a ésta como cosa solamente ligada a las supervivencias ${ }^{44}$. Sin embargo, hay igualmente "tradición" -escrita y oral, pero casi siempre las dos- en el aprendizaje y transmisión de la cultura considerada como de "éliten. El estudio de la llamada literatura popular, con más de una vía intermedia entre lo oral y lo escrito - así, los pliegos denominados de cordel- pone de manifiesto esa dualidad que ha permitido que - desde muy antiguo- se transmitieran relatos por la vista y el oído (como asunto cantado, impreso, o representado en "aleluyas" y cartelones).

También se ha pretendido ver la distinción entre lo "popular" y lo "culto" como una división de la que no hay total consciencia hasta el siglo pasado, y ello sólo es cierto en cuanto al acuñamiento del término de folklore, ya que como ha demostrado Peter Burke tal divorcio de tradiciones puede rastrearse perfectamente desde finales de la Edad Media. Y, se debe añadir, mucho antes.

Jacques Le Goff ha señalado cómo los campesinos que parecen apartados, ausentes de la Literatura de la Edad Media, son -como muchoidentificados con los paganos ("paganus", término latino procedente del griego) por los escritores cristianos, para los cuales "paganus" está ligado -en su sentido- al también latino "gentilis". y al griego "etnikos". San Isidoro lo deja bien claro. Pero estos "paganos" no eran, seguramente, "incultos" ni "primitivos" — como "animales" en su totalidad. Interesaba que se les percibiera como tales desde la estrategia cultural de la élite cristiana que pretendía afianzar su poder político en base a lo religioso. Y que, de hecho, vino a sustituir - hasta en distribución territorial- lo que había sido la maquinaria homologadora del Imperio.

Para lograr esa imposición de un modelo cultural-religioso determinado, los "pensadores" $\longrightarrow$, si se quiere, "ideólogos» - del cristianismo empiezan a depurar y falsear la herencia del mundo clásico hasta apropiár-

44 Julio CARO BAROJA, Palabra, sombra equívoca (Barcelona: Tusquets, 1989), pp. 153-165. 
sela casi por entero. Se demoniza a los "paganos" y se les persigue hasta las villas campestres en que se habían refugiado para matarles si fuera necesario. Villas que quizá fueran más que lugares - ya- de recreo a modo de últimos santuarios de un postrer paganismo reorganizado.

$\mathrm{Y}$ todo porque eran esos "paganos", justamente, los que mayor resistencia ofrecían a la evangelización. La situación era nueva, además, pues en Roma siempre se había vivido pluralmente la religión, hasta el punto de que -como hace notar Momigliano ${ }^{45}$ - no hubo religión romana "oficial" que se enseñara regularmente en las escuelas. Parece que se habría aprendido más desde la "Pequeña" que desde la "Gran Tradición".

Con este giro de fanatismo religioso que imponen los cristianos es cuando aparece, claramente, la cultura no como aglutinante sino como arma para separar. La cultura como manera de recontar la historia y, fundamentalmente, la Cultura — con mayúsculas - frente a las otras tradiciones culturales que son objeto de anatema por "desviadas" y "perniciosas".

La Cultura como poder. Como forma de fortalecerse en él. Como ha escrito Le Goff, estos campesinos procedentes de los "pagos" serán, también, en la Edad Media "la clase peligrosa" "46. Convenía, así, confinarles en el limbo cultural de lo "semi-salvaje" que -aunque reaparezca en el Renacimiento- creo que se inventa, verdaderamente, entonces. En Alfonso X encontraremos a los "gentiles" como aquellos hombres que en una "naif" pseudo-evolución de las creencias "dieron en creer en yerbas y árboles mejor que en piedras $"$ " 7 .

Luego, a finales de la Edad Media, cuando los eclesiásticos reinventen la brujería, se considerará que las prácticas nefandas de brujas y brujos procedían de la pervivencia del paganismo en el campo. Y que el demonio - un dios al revés, ahora, con sus sacerdotes, monjas y misas- encontraba en la ignorancia y salvajismo de los "rústicos" su mejor aliado.

Pero el verdadero peligro era, probablemente, otro. La magia - que también tenía sus tradiciones culta y popular o sus vías de transmisión orales y escritas- rebrotaba en algunos de los más destacados hombres del Renacimiento, atentando contra una separación fundamental: la que una Iglesia usurpadora de las bondades del Imperio había dictaminado entre Religión, Ciencia y Arte, para así colocar en lugar prevalente —como verdaderos

45 Arnoldo Momigliano, De paganos, judíos y cristianos (México: Fondo de Cultura Económica, 1987).

${ }^{46}$ Jacques Le GoFf, Tiempo, trabajo y cultura en el Occidente Medieval (Madrid, 1983), pp. 124-141.

47 Alfonso El SABIO, General Storia (Madrid, 1950); edición de Antonio G. SolALINDE, Libro III, Cap. X-XIII. 
árbitros y jueces - a los administradores del mensaje religioso. El gran peligro era que el paganismo volviera a mezclarlo todo: "Vade retro".

La escisión entre lo "culto" - como elevado, evolucionado y buenoy lo "popular" o "pagano" — como bajo, atrasado y malo- no había hecho más que comenzar.

\author{
LUIS DÍAZ G. VIANA * \\ Departamento de Antropología \\ Instituto de Filología. CSIC
}

"Cultura popular" es un término confuso y un asunto difícil de aprehender. Historiadores y antropólogos se han visto afectados por ello durante mucho tiempo y conocen bien las dificultades que tiene el caracterizar lo que es o no "cultura popular" en uno u otro período de la historia de Europa. De otro lado, aquí se propone que la ainvención" de la "cultura popular" comienza a producirse en nuestro ámbito mucho antes de lo que generalmente se viene suponiendo, con la persecución del paganismo. El propósito de este trabajo consiste en mostrar que la discusión sobre la "cultura popular" tiene más relación con el concepto de "cultura" que con los diferentes significados que demos a las palabras "popular" o "pueblo".

"Popular culture" is a confussing term and an elusive matter. Historians and anthropologists have been concerned with it for ages and know quite well the difficulties in characterizing what is or is not "popular culture" in any period of european history. On the other hand, the author suggests here that the "invention" of "popular culture" starts earlier than supossed, with the persecution of paganism. The aim of this paper is to show that discussion about "popular culture" is more related to the concept of "culture" than to the several meanings of the term "peoplen.

* Quiero agradecer, muy especialmente, las sugerencias que me han ofrecido -a través de largas conversaciones informales, divertidas y fructíferas- amigos y colegas como Isabel Beceiro Pita, Fermín del Pino, Manuel Gutiérrez Estévez y María Cátedra. 